\title{
Effects of inbreeding in three life stages of Drosophila buzzatii after embryos were exposed to a high temperature stress
}

\author{
JESPER DAHLGAARD \& VOLKER LOESCHCKE* \\ Department of Ecology and Genetics, University of Aarhus, Ny Munkegade, B/dg. 540, 8000 Aarhus C, Denmark
}

\begin{abstract}
The interaction between inbreeding and high-temperature stress was examined in the cactophilic fruit fly, Drosophila buzzatii. Embryos of four inbreeding levels $(F=0, F=0.25$, $F=0.375, F=0.5$ ) were either maintained at $25^{\circ} \mathrm{C}$ throughout egg-to-adult development or were exposed to $41.5^{\circ} \mathrm{C}$ for $110 \mathrm{~min}$ at an age of $20 \mathrm{~h}$. Hatching, larva-to-pupa survival, pupato-adult survival, and egg-to-adult survival were estimated. Heat shock reduced hatching rates, but survival to adulthood for individuals that hatched was unaffected by the heat shock. Inbreeding reduced the proportion of eggs hatching in the $25^{\circ} \mathrm{C}$ control group only. For larvato-pupa and pupa-to-adult survival there was no interaction between inbreeding and stress. The effect of inbreeding on egg-to-adult survival was stronger in the $25^{\circ} \mathrm{C}$ control group compared with the group exposed to heat shock. The results imply environmental dependency of inbreeding depression and suggest that stress tolerance may not always be reduced by inbreeding. The thermal microenvironment of cactus rots in the field was assessed by measuring temperatures inside 17 rots. Internal rot temperatures varied with a maximum temperature of $48^{\circ} \mathrm{C}$ during the day. Selection for temperature tolerance in nature may have depleted genetic variation for this trait limiting the effect of inbreeding on thermal resistance.
\end{abstract}

Keywords: Drosophila buzzatii, embryos, heat-shock tolerance, inbreeding, stress.

\section{Introduction}

Inbreeding may affect fitness negatively in numerous ways (Wright, 1977; Charlesworth \& Charlesworth, 1987; Falconer, 1989). One effect may be reduced stress tolerance if the tolerance trait is dominant or overdominant (Parsons, 1971, 1987; Hoffmann \& Parsons, 1991), or alternatively, if tolerance covaries with overall fitness. The ability of Drosophila subobscura adults to acclimate during development to a high-temperature stress was reduced by inbreeding (Maynard Smith, 1956) as was cold-shock tolerance in adult $D$. melanogaster (Ehiobu et al., 1989). Heatshock tolerance was also found to be reduced with increased inbreeding in adult $D$. buzzatii (Dahlgaard et al., 1995), even though in nature this species experiences moderate levels of inbreeding (Prout \& Barker, 1993) and is exposed to high temperatures. It is unknown if embryo heat-shock tolerance in $D$. buzzatii is affected by inbreeding.

\footnotetext{
*Correspondence. E-mail: volker@pop.bio.aau.dk
}

The average homozygosity level in a cohort of inbred individuals is expected to decrease at successive life stages because of natural selection (Falconer, 1989). If stress tolerance covaries with the amount of inbreeding depression, susceptibility to stress may be highest at earlier life stages when not much selection has occurred yet. On the other hand, if tolerance to a stress is mainly controlled by specific genes, distinct from those causing inbreeding depression, a change in tolerance after inbreeding will solely depend on the genetic architecture of the trait.

In nature, $D$. buzzatii oviposits on cactus rots that are exposed to the sun during most of the day. Thus, embryos experience high temperatures for at least part of the day (Krebs \& Loeschcke, 1994; Loeschcke et al., 1994). The degree to which different life stages are exposed to extreme temperatures possibly varies. Variation in stress intensities across life stages may result in correspondingly different selection intensities for heat tolerance. Embryos and pupae cannot escape behaviourally 
from the most extreme temperatures and adaptive differentiation in response to heat and cold stress was found among pupae but not adults of $D$. pseudoobscura (Coyne et al., 1983).

If different genes affect heat tolerance in different life stages or if the expression of specific genes varies with the developmental stage, differences in selection pressure for heat tolerance among life stages may cause the amount of genetic variation affecting survival to differ at various life stages. The lack of correlation between different life stages in relative resistance to heat shock among populations of D. buzzatii (Krebs \& Loeschcke, 1995, 1996) suggests that the genes involved or their expression are at least partly different. Expression of genes coding for different size classes of heat-shock proteins important for resistance (Welte et al., 1993; Parsell \& Lindquist, 1994) changes through development (Bergh \& Arking, 1984; Parsell \& Lindquist, 1994). Thus, it is possible that the amount of genetic variation for heat tolerance varies among life stages and that heat-shock tolerance of different life stages is affected differently by inbreeding.

Here we estimate survival through different developmental stages from embryos to adults at four inbreeding levels $(F=0, F=0.25, F=0.375$ and $F=0.5$ ) with half the embryos exposed to a hightemperature stress $20 \mathrm{~h}$ postlaying.

\section{Materials and methods}

The $D$. buzzatii population used here originated from 22 isofemale lines collected from Tenerife, Canary Islands, December 1992. Equal numbers of males and females from each line were pooled to produce a mass population which was maintained for 15 generations at $25^{\circ} \mathrm{C}$ under continuous light until use (with 15 bottles per generation, $20-30$ pairs per bottle using instant Drosophila medium from Carolina Biological Supply).

To assess the thermal environment at the collection locality, temperatures within 17 cactus cladodes were measured on two sunny December afternoons, by placing electrodes connected to a data logger into cactus rots. The temperature was recorded each hour. Rots afterwards were brought to the laboratory and checked for emerging flies every two days over four weeks.

Many independently derived inbred and outbred lines (without replication) of three inbreeding levels $(F=0, F=0.25$ and $F=0.375)$ were prepared from the mass population applying the same mating design (full-sib matings) as described in Dahlgaard et al. (1995). Before the experiment all pairs were placed separately in inverted Eppendorf vials with an agar-yeast-ethanol-acetic acid egg-collecting medium placed in the lid. Females oviposited for $7 \mathrm{~h}$ after which all lids were replaced.

Lids, containing 10-30 embryos, were split randomly into two groups; a control group, kept at $25^{\circ} \mathrm{C}$, and a group exposed to a high-temperature stress. To reduce density effects, lids with fewer or more embryos were discarded. At $20 \pm 3.5$ hours post laying, embryos assigned to the high-temperature treatment were placed in a large Petri dish containing moistened filter paper, and placed in an incubator at $41.5^{\circ} \mathrm{C}$ for $110 \mathrm{~min}$. During heat exposure the Petri dishes were rotated at regular intervals and afterwards were returned to $25^{\circ} \mathrm{C}$. The entire experiment was replicated twice, separated in time by 2 months.

At the time of stressing, gastrulation would have occurred in all embryos. After gastrulation, the complete heat-shock response is acquired in $D$. melanogaster and survival from heat shock is increased and remains constant during embryo development (Bergh \& Arking, 1984). Here embryos were not pretreated because pretreatment induces the production of hsp70 which is detrimental to growth and/or cell division (Feder et al., 1992) and because thermotolerance of embryos in contrast to adults is lost within a few minutes when hsp70 is inactivated by sequestration into granules (Parsell \& Lindquist, 1994).

The number of embryos hatching in the control group was scored $38 \mathrm{~h}$ postlaying and in the heatstressed group another $12 \mathrm{~h}$ later ( $50 \mathrm{~h}$ postlaying), because heat stress significantly delays hatching (Bergh \& Arking, 1984; Krebs \& Loeschcke, 1995). After hatching was scored, the egg-collecting medium containing larvae was transferred to fresh food vials which were kept at $25^{\circ} \mathrm{C}$ until emergence. The number pupating and eclosing was counted. The data were the proportion of eggs hatching, larva-to-pupa survival, pupa-to-adult survival and overall egg-to-adult survival. All data, recorded as the proportion surviving in each vial, were arcsine square-root transformed for analysis of variance, with the stress and control treatment as fixed factors and inbreeding as a continuous variable (GLM procedure, SAS Institute, 1989). Because the number of individuals varied among replicates, and density effects may affect survival, numbers were included in the analyses as a covariate. Additionally, effects of inbreeding on survival of the different developmental stages of stressed and unstressed embryos were analysed separately by linear regression. Preliminary analyses indicated that the model was not improved 
by the addition of a nonlinear term. Differences between regression coefficients were tested by examining treatment $\times$ inbreeding interactions (GLM procedure, SAS Institute, 1989) on both arcsine square-root and log-transformed data. The log transformation did not change the results qualitatively and only the analysis based on arcsine square-root transformed data is presented. Results were very similar between the two blocks of replicates; however, block effects were significant for pupato-adult survival $(P<0.05)$ and egg-to-adult survival $(P<0.001)$. Interactions with block were rare (two significant interactions out of 12 possible ones, a block $\times$ inbreeding and a block $\times$ treatment interaction for egg-to-adult survival) and where present they were small $(P<0.05)$. Interactions with blocks were pooled into the error term and thus served only to make significance testing of the regressions of inbreeding on survival conservative. The number of larvae was negatively correlated with pupato-adult survival; some pupae drowned when larval density was high. The negative correlation of egg number with egg-to-adult survival also was caused by drowning (the number of larvae is positively correlated with the number of embryos).

\section{Results}

Temperatures within 17 cactus cladodes (measured from $08: 00$ to $18: 00$ hours) ranged from $11.4^{\circ} \mathrm{C}$ to $48.3^{\circ} \mathrm{C}$ (Fig. 1). Within-rot variation in temperature was high, in some cases up to $10^{\circ} \mathrm{C}$ (results not

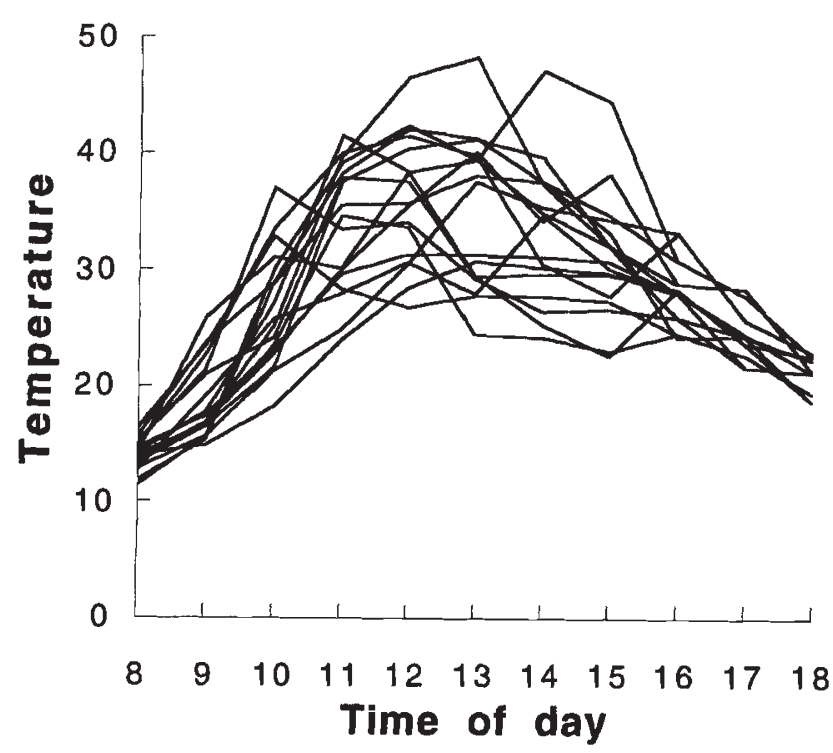

Fig. 1 Temperature plotted over $10 \mathrm{~h}$ in 17 necrotic cactus cladodes on Tenerife, Canary Islands, December 1992. shown). Flies were observed emerging from several rots after these were brought to the laboratory, even in the case of the rot which attained $48.3^{\circ} \mathrm{C}$.

The proportion of embryos that hatched was reduced significantly by exposure to heat stress $\left(F_{1,353}=40.1, P<0.001\right.$; Fig. 2$)$ and by inbreeding $\left(F_{1,353}=14.3, P<0.001\right)$. However, only within the nonstressed group was the inbreeding effect significant in a regression model (Table 1). This difference between treatments was reflected by a significant interaction term between inbreeding and treatment $\left(F_{1,353}=9.3, P<0.01\right)$.

No temperature treatment with inbreeding level interactions were present in further developmental stages. In the ANOVA, inbreeding reduced larvato-pupa survival in the stress and nonstress treatments $\left(F_{1,287}=7.2, P<0.01\right.$; Fig. 3 and Table 1$)$, as was the case for pupa-to-adult survival $\left(F_{1,235}=5.8\right.$, $P<0.05$; Fig. 4). Heat shock of embryos had no effect on larva-to-pupa survival $\left(F_{1,287}=0.2, \mathrm{NS}\right.$; Fig. 3 and Table 1).

Overall, egg-to-adult survival was significantly reduced by exposure of embryos to heat stress $\left(F_{1,383}=36.2, \quad P<0.001\right) \quad$ and $\quad$ by inbreeding $\left(F_{1,383}=35.7, P<0.001\right)$. The latter effect was larger

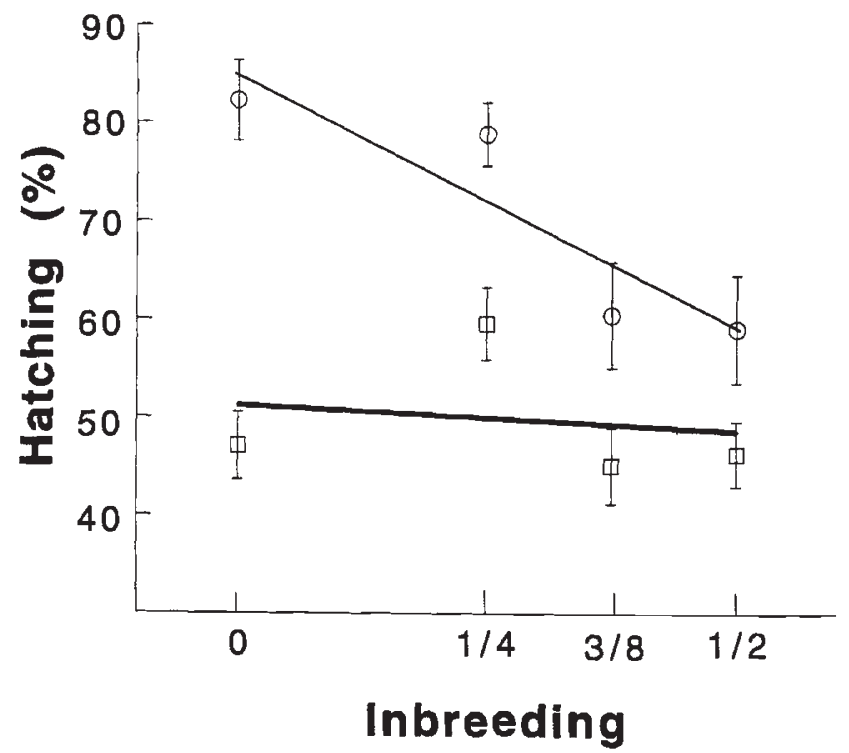

Fig. 2 Percent of embryos hatching $( \pm \mathrm{SE})$ in Drosophila buzzatii at four inbreeding levels. Circles indicate that embryos were kept at $25^{\circ} \mathrm{C}$, squares indicate that embryos were exposed to $41.5^{\circ} \mathrm{C}$ for $110 \mathrm{~min}(n=28-33$ lids in the unstressed control group and $n=52-55$ lids in the experimental group exposed to heat stress). All lids contained 10-30 embryos. Lines show the regression of $F$ on survival in the environment with stress (broad line) and in the one without (thin line). 
Table 1 Regression equations for $F$ (inbreeding coefficient) on the proportion of embryos hatching, larvato-pupa survival, pupa-to-adult survival and egg-to-adult survival in Drosophila buzzatii. Flies of four inbreeding groups $(F=0, F=0.25, F=0.375, F=0.5$ ) were exposed to heat-stress as embryos for $110 \mathrm{~min}$ at $41.5^{\circ} \mathrm{C}$.

Regression equation, $F$ on survival: $Y_{i}=\beta_{0}+\beta_{1}\left(F_{i}\right)$

\begin{tabular}{|c|c|c|c|}
\hline & $\beta_{00}( \pm \mathrm{SE})$ & $\beta_{1}( \pm \mathrm{SE})$ & $\begin{array}{c}P \text {-value for } \\
H_{0}: \beta_{1}=0\end{array}$ \\
\hline \multicolumn{4}{|l|}{ Hatching rate } \\
\hline Without stress & $0.85(0.04)$ & $-0.52(0.13)$ & $<0.001$ \\
\hline With stress & $0.51(0.03)$ & $-0.05(0.10)$ & 0.590 \\
\hline \multicolumn{4}{|c|}{ Larvae-to-pupae survival } \\
\hline Without stress & $0.87(0.04)$ & $-0.23(0.11)$ & 0.037 \\
\hline With stress & $0.85(0.03)$ & $-0.24(0.10)$ & 0.019 \\
\hline \multicolumn{4}{|c|}{ Pupae-to-adult survival } \\
\hline Without stress & $0.85(0.02)$ & $-0.02(0.06)$ & 0.690 \\
\hline With stress & $0.87(0.03)$ & $-0.14(0.08)$ & 0.095 \\
\hline \multicolumn{4}{|c|}{ Egg-to-adult survival } \\
\hline Without stress & $0.66(0.02)$ & $-0.40(0.08)$ & $<0.001$ \\
\hline With stress & $0.45(0.03)$ & $-0.19(0.08)$ & 0.016 \\
\hline
\end{tabular}

in the control treatment (Fig. 5 and Table 1), where the reduction in survival because of inbreeding was twice that estimated for the heat-stressed group $\left(\beta_{\text {control }}=-0.40\right.$ and $\left.\beta_{\text {stress }}=-0.19\right)$. The interaction term between inbreeding and treatment was significant $\left(F_{1,383}=5.6 ; P<0.05\right)$.

Number of larvae was negatively correlated with pupa-to-adult survival $(r=-0.30$, Pearson's linear correlation coefficient, $P<0.0001)$ and number of embryos was negatively correlated with egg-to-adult survival $(r=-0.21, \quad P<0.0001)$. Numbers of embryos and larvae were included in the analysis of variance as a covariate.

Density, i.e. the number of embryos, was similar in the four inbreeding groups $(F=0): 21.78 \pm 0.93$; $(F=0.25): \quad 20.48 \pm 0.83 ; \quad(F=0.375): 21.80 \pm 0.83$; $(F=0.5): 20.10 \pm 0.89$.

\section{Discussion}

Heat-shock tolerance of Drosophila buzzatii embryos was not reduced by inbreeding in contrast with a significant negative effect of inbreeding on adult heat-shock tolerance (Dahlgaard et al., 1995). Heat shock reduced the inbreeding depression by diminishing fitness differences among embryos of the four inbreeding levels, revealing environmental dependency

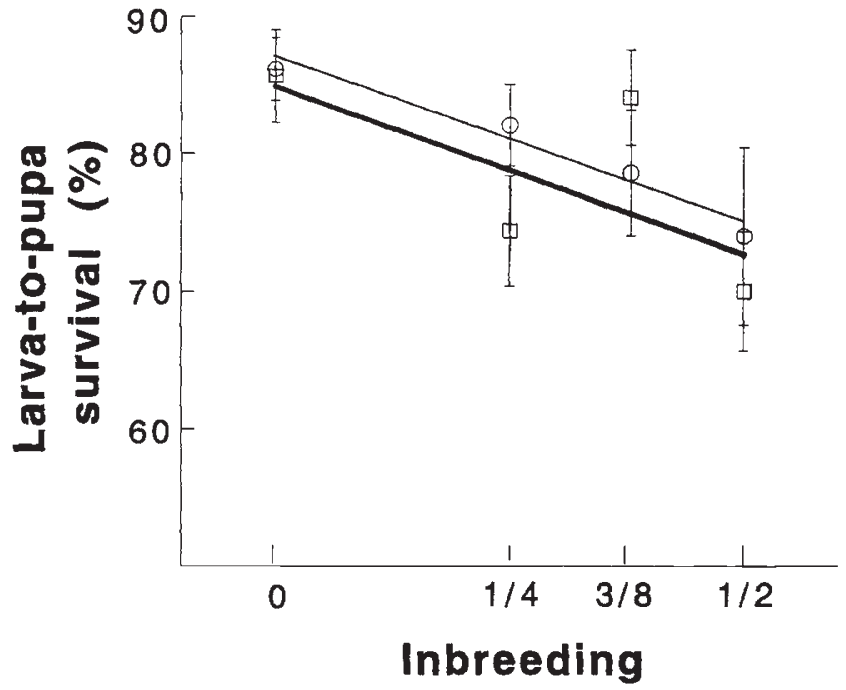

Fig. 3 Percent larva-to-pupa survival $( \pm \mathrm{SE})$ in Drosophila buzzatii at four inbreeding levels. Circles indicate larvae collected from embryos kept at $25^{\circ} \mathrm{C}$, squares indicate larvae collected from embryos exposed to $41.5^{\circ} \mathrm{C}$ for $110 \min (n=24-41$ in the unstressed control group and $n=40-44$ in the experimental group where larvae were heat-exposed as embryos). Lines show the regression of $F$ on survival in the environment with stress (broad line) and in the one without (thin line).

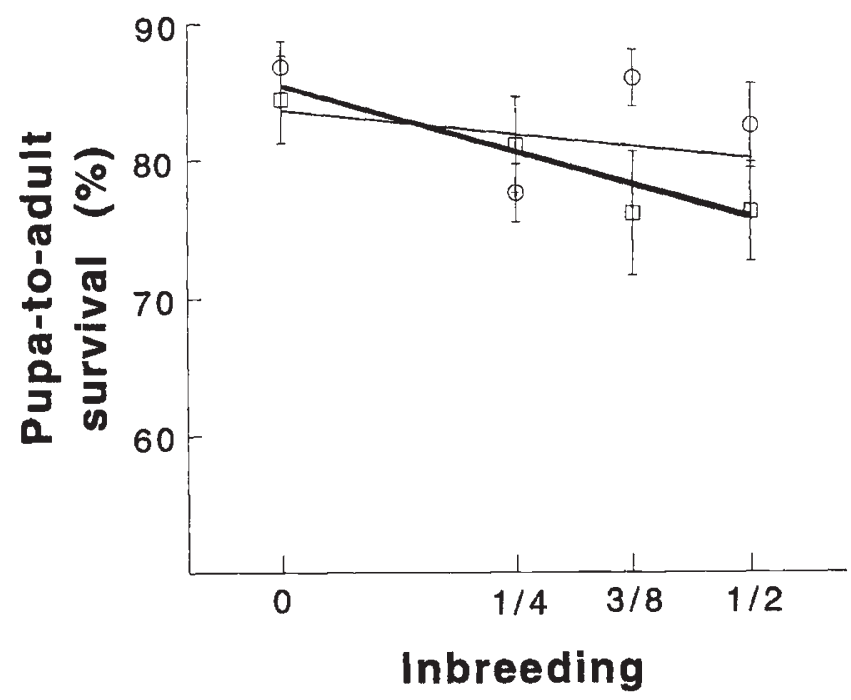

Fig. 4 Percent pupa-to-adult survival $( \pm \mathrm{SE})$ in Drosophila buzzatii at four inbreeding levels. Circles indicate pupae from the control group (embryos kept at $25^{\circ} \mathrm{C}$ ), squares indicate pupae from the experimental group (embryos exposed to $41.5^{\circ} \mathrm{C}$ for $\left.110 \mathrm{~min}\right)(n=35-50$ in the control group and $n=32-40$ in the experimental group). Lines show the regression of $F$ on survival in the environment with stress (broad line) and in the one without (thin line). 


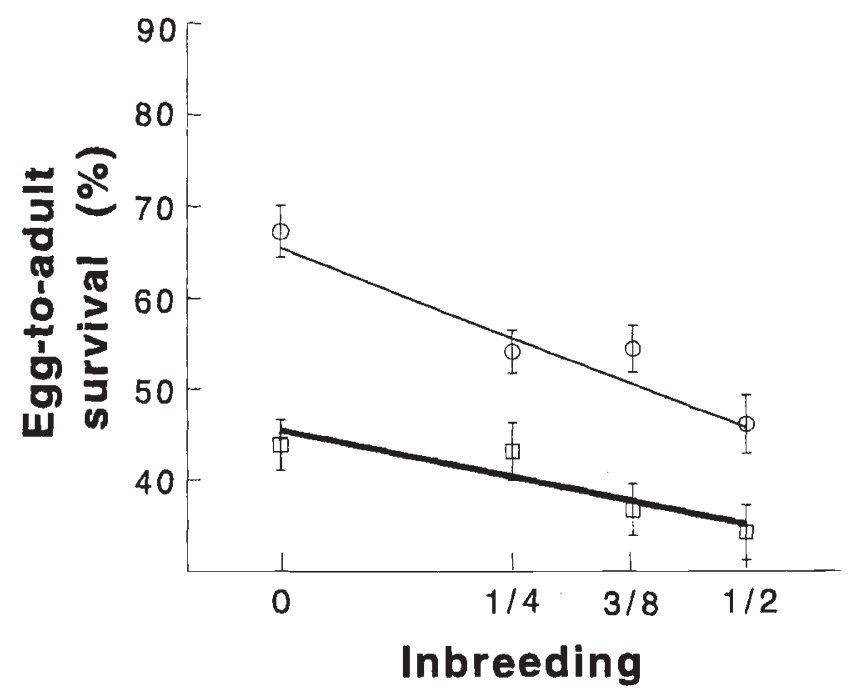

Fig. 5 Percent egg-to-adult survival $( \pm \mathrm{SE})$ in Drosophila buzzatii at four inbreeding levels. Circles indicate embryos kept at $25^{\circ} \mathrm{C}$, squares indicate embryos exposed to $41.5^{\circ} \mathrm{C}$ for $110 \mathrm{~min}$ ( $n=37-63$ lids in the unstressed group and $n=41-52$ in the group exposed to heat stress). Lines show the regression of $F$ on survival in the environment with stress (broad line) and in the one without (thin line).

of inbreeding depression in a direction opposite to that expected. Once individuals hatched, inbreeding affected future survival similarly for individuals that were stressed or held at constant $25^{\circ} \mathrm{C}$. Heat shock reduced the probability that embryos hatched, but survival of subsequent life stages was not affected by heat shock.

Inbreeding depression may increase with environmental harshness over applies to a range of stress levels (Komaki, 1982; Levin, 1984; Pray et al., 1994; Hauser \& Loeschcke, 1996). However, when a stress is extremely severe, differences in survival among inbreeding groups may be diminished when the stress level is elevated further (Dahlgaard et al., 1995). It is possible that the lack of observable inbreeding effects on embryo heat-shock tolerance relates to the mode of 'selection imposed by the stressful environment. Hauser et al., (1994) showed that when the mean of a trait decreases with increased inbreeding the variance may increase. It is possible that inbred embryos that died from the heat shock were predominantly those which also had a low probability of hatching in the unstressed environment. Thus, when a severe stress kills a high proportion of the individuals, an increase in the variance with inbreeding would create the possibility of some individuals in all inbreeding groups withstanding the stress treatment.
Under an additive model with rapidly increasing levels of inbreeding in a constant environment, the genetic variance between lines for $F=0.5$ is expected to be almost twice that for $F=0.25$. The variance in hatching rate in the unstressed environment was 0.084 for $F=0.25$ and 0.151 for $F=0.5$ $\left(F_{28,43}=1.80 ; P<0.05\right)$. In the stressful environment variances generally were smaller and differences in variance among inbreeding levels were not significant. Thus, given some correlation between hatching in the two environments, it is possible that the increased variance observed in the unstressed environment with increased inbreeding enabled some individuals in all inbreeding groups to withstand the stress.

In contrast to adults, embryos are immobile and unable to escape physically from stressful conditions. Selection against alleles affecting tolerance in embryos may be more intense than selection against corresponding alleles affecting tolerance in adults. Variation at loci affecting heat tolerance in embryos may therefore be low compared to that in adults, limiting the effect of inbreeding on embryo heat tolerance. Temperature measurements within cactus rots in the field suggest that embryos in nature are subjected to selection for heat tolerance. Some of the rots (Fig. 1) that produced flies, not only reached the heat-shock temperature applied in this experiment, $41.5^{\circ} \mathrm{C}$, but also remained longer at this or higher temperatures than the experimental flies. Embryo development in $D$. buzzatii lasts more than $24 \mathrm{~h}$ and embryos therefore can not avoid the high temperatures during early afternoon. However, in nature females oviposit during late afternoon and the most sensitive period of the embryonic development therefore takes place when temperatures are not extreme. The following day at noon embryos are older and tolerance is increased and possibly resembles that of the experimental embryos as these were of similar age.

The lack of an inbreeding effect on embryo heatshock tolerance in $D$. buzzatii shows that heat-shock resistance is not influenced by inbreeding depression in the environment without stress. That homozygosity per se does not reduce heat-shock tolerance is also intimated by the situation wherein actual differences in homozygosity levels among inbreeding groups probably were larger in the experiment with embryos than in the one with adults (Dahlgaard et al., 1995), for three reasons. First, differences in homozygosity level among inbreeding groups may be greater immediately after fertilization, before selection has occurred. Secondly, compared to the population used in Dahlgaard et al. (1995), the

(C) The Genetical Society of Great Britain, Heredity, 78, 410-416. 
population used here was initiated with more founders, and thirdly, was maintained for a shorter period in the laboratory prior to the experiment. This may have allowed less inbreeding to occur preceding the experiment. Because heat-shock tolerance of adults did decrease with increased inbreeding (Dahlgaard et al., 1995), some of the genes for adult heat tolerance may specifically be expressed in adults and not in embryos. For instance, increased homozygosity for temperature-sensitive alleles (Langridge, 1962, 1968) or homozygosity at loci involved in the heat-shock response (Parsell \& Lindquist, 1994), only expressed in adults, may have reduced adult heat tolerance. Alternatively, relative effects of specific gene products on survival may vary between life stages. For instance, one of the major gene products responsible for heat tolerance in young embryos of $D$. melanogaster (Welte et al., 1993) and presumably also in adults (own results), hsp70, is hardly important for older embryos, i.e. 12-h-old and 18-h-old embryos (Welte et al., 1993), possibly because hsp70 is detrimental to growth and cell division.

Our results show not only that inbreeding depression is environmentally dependent but also that reduced stress tolerance with increased inbreeding is not universal. The effect of inbreeding on stress tolerance may depend on the stress type and in particular on whether selection for the tolerance trait occurs in nature. Selection for heat resistance at the embryo stage may have depleted genetic variation and reduced the potential effects of inbreeding on heat-shock tolerance. The genetic architecture behind the trait is important too, i.e. whether tolerance is correlated with general fitness and therefore possibly with inbreeding depression, or whether tolerance is determined by only a few genes. Here, overall tolerance did not covary with the amount of inbreeding depression and may have been determined predominantly by specific tolerance genes. The genetic architecture of most stress-resistance traits has been suggested to be additive (Hoffmann \& Parsons, 1991). Because embryo heat-shock tolerance is not affected by inbreeding this may suggest additivity of allele effects at loci determining resistance.

\section{Acknowledgements}

We thank Ary Hoffmann, Bob Krebs and Kuke Bijlsma for helpful comments on the manuscript. Also we are grateful to Bob Krebs for discussions and assistance during recordings of cactus-rot temperatures. This study was supported by a grant from the Aarhus University Research Foundation to JD and in part by the Danish Natural Sciences Research Council (grant no. 94-01-631).

\section{References}

BERGH, S. AND ARKING, R. 1984. Developmental profile of the heat-shock response in early embryos of Drosophila. J. Exp. Zool., 231, 379-391.

CHARLESWORTH, D. AND CHARLESWORTH, B. 1987. Inbreeding depression and its evolutionary consequences. Ann. Rev. Ecol. Syst., 18, 237-268.

COYNE, J. A., BUNDGAARD, J. AND PROUT, T. 1983. Geographic variation of tolerance to environmental stress in Drosophila pseudoobscura. Am. Nat., 122, 474-488.

DAHLgAARD, J., KREBS, R. A. AND LOESCHCKE, V. 1995. Heat-shock tolerance and inbreeding in Drosophila buzzatii. Heredity, 74, 157-163.

EHIOBU, N. G., GODDARD, M. E. AND TAYLOR, J. F. 1989. Effect of rate of inbreeding on inbreeding depression in Drosophila melanogaster. Theor. Appl. Genet., 77, 123-127.

FAlCONER, D. S. 1989. Introduction to Quantitative Genetics, 3rd edn. John Wiley and Sons, New York.

FEDER, J.H., ROSSI, J.M., SOLOMON, N. AND LINDQUIST, S. 1992. The consequences of expressing hsp70 in Drosophila cells at normal temperatures. Genes Devel., 6, 1402-1413.

HAUSER, T. P. AND LOESCHCKE, v. 1996. Drought stress and inbreeding depression in Lychnis flos-cuculi (Caryophyllaceae). Evolution, 50, 1119-1126.

HAUSER, T. P., DAMGAARD, C. AND LOESCHCKE, v. 1994. Effects of inbreeding in small plant populations: expectations, and implications for conservation. In: Loeschcke, V., Tomiuk, J. and Jain, S. K. (eds) Conservation Genetics, pp. 115-130. Birkhäuser, Basel.

HOFFMANN, A. A. AND PARSONS, P. A. 1991. Evolutionary Genetics and Environmental Stress. Oxford Science Publications, Oxford.

KOMAKI, M. K. 1982. Inbreeding depression and concealed deleterious mutations in buckwheat populations, Fagopyrum esculentum. Jap. J. Genet., 57, 361-370.

KREBS, R. A. AND LOESCHCKE, V. 1994. Response to environmental change: Genetic variation and fitness in Drosophila buzzatii following temperature stress. In: Loeschcke, V., Tomiuk, J. and Jain, S.K. (eds) Conservation Genetics, pp. 309-322. Birkhäuser, Basel.

KREBS, R. A. AND LOESCHCKE, V. 1995. Resistance to thermal stress in preadult Drosophila buzzatii: variation among populations and changes in relative resistance across life stages. Biol. J. Linn. Soc., 56, 517-531.

KREBS, R. A. AND LOESCHCKE, v. 1996. Selection for increased resistance and acclimation to thermal stress in Drosophila buzzatii. Genetics, 142, 471-479.

LANGRIDGE, J. 1962. A genetic and molecular basis for heterosis in Arabidopsis and Drosophila. Am. Nat., 96, 5-27. 
LANGRIDGE, J. 1968. Thermal responses of mutant enzymes and temperature limits to growth. Mol. Gen. Genet., 103, 116-126.

LEVIN, D. A. 1984. Inbreeding depression and proximitydependent crossing success in Phlox drummondii. Evolution, 38, 116-127.

LOESCHCKE, V., KREBS, R. A. AND BARKER, J. S. F. 1994. Genetic variation for resistance and acclimation to high temperature stress in Drosophila buzzatii. Biol. J. Linn. Soc., 52, 83-92.

MAYNARD SMITH, J. 1956. Acclimatization to high temperatures in inbred and outbred Drosophila subobscura. J. Genet., 54, 497-505.

PARSELl, D. A. AND LINDQUiST, S. 1994. Heat-shock proteins and stress tolerance. In: Morimoto, R. I., Tissieres, A. and Georgopoulos, C. (eds) The Biology of Heat-shock Proteins and Molecular Chaperones, pp. 457-494. Cold Spring Harbor Laboratory Press, New York.

PARSONS, P. A. 1971. Extreme-environment heterosis and genetic loads. Heredity, 26, 579-583.

PARSONS, P. A. 1987. Evolutionary rates under environmental stress. Evol. Biol., 21, 311-347.

PRAY, L. A., SCHWARTZ, J. M., GOODNJGHT, C.J. AND STEVENS, L. 1994. Environmental dependency of inbreeding depression: Implications for conservation biology. Conserv. Biol., 8, 562-568.

PRoUT, T. AND BARKer, J. S. F. 1993. F-statistics in Drosophila buzzatii: selection, population size and inbreeding. Genetics, 134, 369-375.

SAS InSTITUTE 1989. SAS/Stat Users Guide. SAS Institute Inc., Cary, NC.

welte, M. A., TETRault, J. M., Dellavalle, R. P. AND LINDQUIST, S. L. 1993. A new method for manipulating transgenes: engineering heat tolerance in a complex, multicellular organism. Curr. Biol., 3, 842-853.

WRIGHT, s. 1977. Evolution and the Genetics of Populations, vol. 3, Experimental Results and Evolutionary Deductions. University of Chicago Press, Chicago. 